\title{
Investigation of Automatic Voltage Regulator for a Ship's Synchronous Generator
}

\author{
Nikolay F. Djagarov ${ }^{1 *}$, Todor P. Lazarov ${ }^{2}$ \\ ${ }^{1-2}$ Nikola Vaptsarov Naval Academy
}

\begin{abstract}
This paper deals with the field current control method of a synchronous generator for ships using a compound type electronic automatic voltage regulator (AVR) in order to control output voltage of the generator. An original AVR scheme, which uses proportional-integral-differential control and pulsewidth modulation scheme to control the output voltage of the compound system, is presented. The scheme of this AVR and the results from its tests, which show good static and dynamic capabilities, are adduced and described.
\end{abstract}

Keywords - Automatic voltage regulator, compound excitation system, proportional-integral-differential regulator, ship's synchronous generator, width impulse modulation.

\section{INTRODUCTION}

Classification organizations impose requirements towards the quality of the generated electrical power from ships' synchronous generators in static and dynamic modes of work. Excitation control of synchronous generators defines that quality mostly. Hence, this is the reason for the increased attention paid to excitation controllers. Over the past few years, multiple automatic voltage regulators (AVR) have been developed. Their use has helped to implement different methods of automatic control and test various electronic components. This allowed obtaining the stability and good regulation of the ship's electric power system.

Voltage regulators for synchronous generators must satisfy the following conditions: regulation to counter disturbances must have high-speed regulators; there should be no derivation from the set voltage in stationary mode; in the short-cut the excitation must be controlled in order to provide a sufficient lasting current which is needed for selective protection; the rated voltage must be easily adjustable on the regulator; proper sharing of reactive load must be assured where several generators are connected in parallel.

In [1], a ship's compound type digital AVR with a proportional-integral (PI) controller and a regulator controlled by pulse-width modulation (PWM) is presented. In [2], an AVR for a synchronous generator in industries applications is developed. A thyristor controller is used to control the excitation voltage. In [3], a self-design model of an automatic voltage regulator with the criteria of performance indices recommended in IEEE Std 421.5 is developed. In [4], a comparative analysis of different types of synchronous generator voltage controllers is presented. Traditional regulation structures based on PID-type controllers are taken into consideration. A new type of voltage controller, based on forced dynamics control
(FDC), is proposed. Contrary to traditional control structures or fuzzy controllers, FDC is a model-based control technique. In [5], the excitation control system in the operation of a generator is presented. The topic of this paper involves the design and construction of excitation control (AVR) for the synchronous generator.

To improve the stability performance of marine power systems, a power system stabilizer (PSS) is introduced [6] into the traditional marine generator excitation system with an automatic voltage regulator. The PSS uses auxiliary stabilizing signals to control the excitation system so as to improve the dynamic performance of marine power systems. This is achieved by the damping of system oscillations. A fast adaptive power system stabilizer is proposed [7] in which an additional control signal is calculated by optimal singular adaptive observer.

A compound-type automatic voltage regulator for a ship's synchronous generator is presented in [8]. The circuit solutions of the suggested AVR as well as some of the experimental results from testing the regulator are shown in this paper.

\section{SCHEME OF A COMPOUND EXCITATION SYSTEM}

In Fig. 1, the investigated scheme of a compound excitation system with an automatic voltage regulator (AVR) is shown. The excitation coil $W_{f}$ of the synchronous generator (SG) receives power from the rectifier, which is powered by a secondary coil $W_{2}$ of the compound transformer CT. The compound transformer has two initial coils - a current one $\left(W_{I}\right)$ and a voltage one $\left(W_{U}\right)$. The correct electromagnetic summation of the initial coils' signals is done by the compound element (capacitor $C$ ). It converts coil $W_{U}$ from a voltage source into a current source and also displaces the phase (by approximately $90^{\circ}$ ) of the voltage signal. To provide a reliable initial self-excitation of the synchronous generator, an additional coil $W_{0}$, which powers the excitation coil $W_{f}$ through a rectifier, is provided.

The compound transformer is designed to provide a higher voltage than the nominal one within the range from an idle to an initial load (Fig. 2). The automatic voltage regulator selects the redundant power above the nominal voltage - the shaded area of the terminal characteristic of the synchronous generator (Fig. 2) [9]. This is done through a field effect transistor (FET) which is a bypass of the excitation coil $W_{f}$ and is controlled by pulse-width modulation.

\footnotetext{
* Corresponding author.

E-mail address: jagarov@ms.ieee.bg
} 


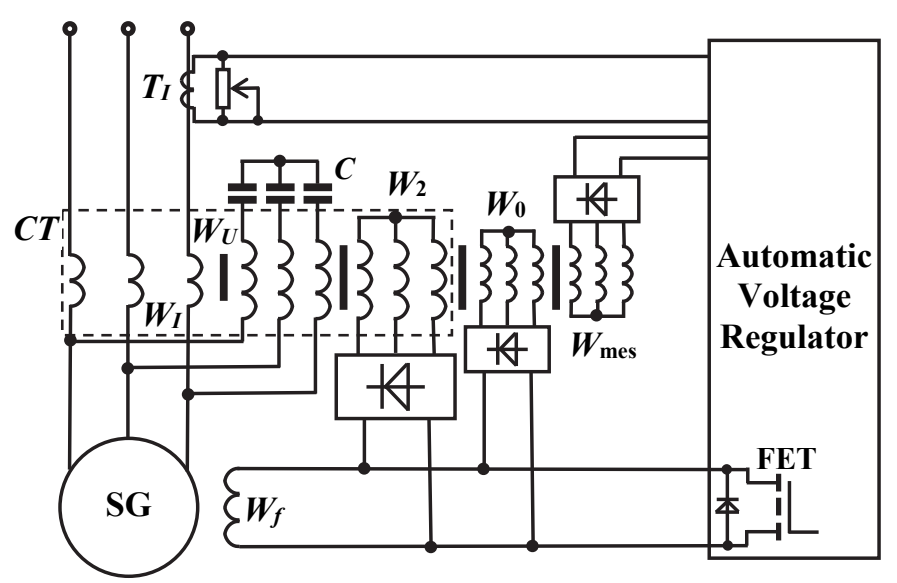

Fig. 1. Scheme of a compound excitation system with AVR.

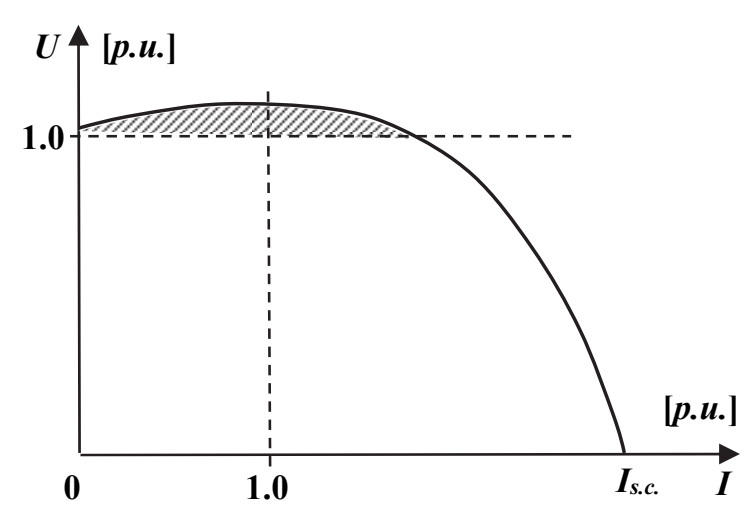

Fig. 2. Output voltage-current characteristics of a synchronous generator.

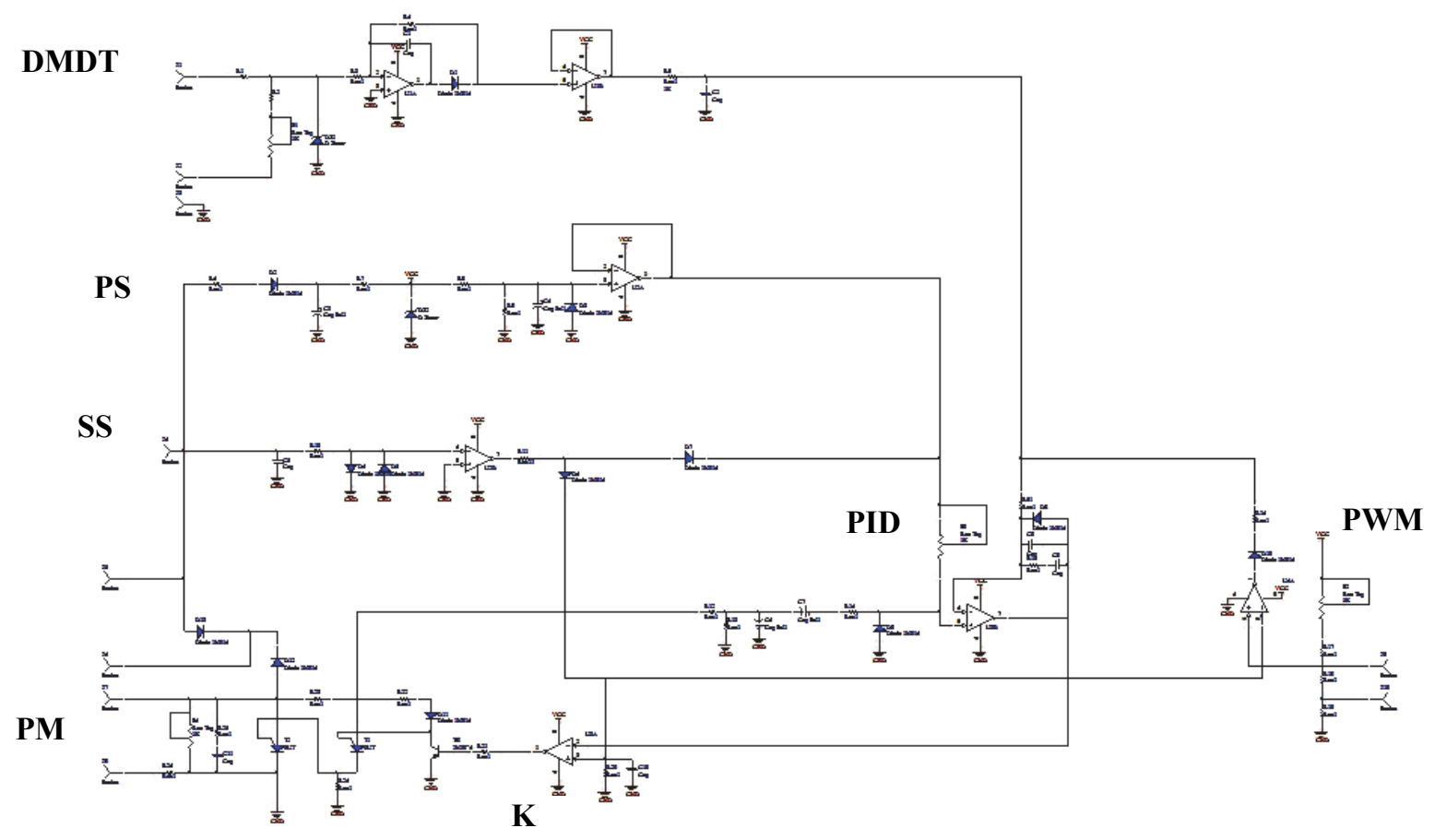

Fig. 3. Electronic scheme of an automatic voltage regulator.

\section{ELECTRONIC SCHEME OF AN AUtOMATIC VOLTAGE REGULATOR}

In Fig. 3, electronic scheme of an automatic voltage regulator is presented.

In this scheme, the following indications are shown:

DMDT - device for measurement and droop tune;

PS - power supply;

$\mathrm{SS}$ - synchronization scheme;

PM - power module;

PID - proportional-integral-differential controller;

PWM - pulse-width modulation scheme;

$\mathrm{K}$ - comparator.
The automatic voltage regulator measures the voltage of the generator and the change in the reactive current and regulates the voltage of excitation in a such a way that the generator's voltage is maintained in a state which is at least $\pm 2 \%$ accurate as it ensures the static character at the reactive loading within the above-mentioned $2 \%$. The voltage regulator influences the voltage as it lowers the generator's current through the resistors connected to it. The regulator works on the base of the width-impulse principle, as it regulates the width of the impulses towards the excitation coil and thus regulates the amount of the rotor current. The amount of the basic stabilized voltage, which is compared to the generator's voltage, is changed by means of the potentiometer of the supplying plate. 
Fig. 4 presents the device for measurement and droop tune (DMDT). The generator's voltage $U_{\mathrm{g}}$ enters the automatic regulator, and at the other end, a voltage which is proportional to the pilot voltage $U_{\text {ref }}$ is applied. The difference between the generator's voltage $U_{\mathrm{g}}$ and the pilot voltage $U_{\text {ref }}$

$$
\Delta U= \pm\left(U_{\mathrm{g}}-U_{\mathrm{ref}}\right)
$$

is sent to the PID controller (Fig. 3).
Comparator is an electronic scheme with an analogue input and impulse output, i.e., the PID controller sends impulses with certain length and amplitude based on the input voltage to it. The output impulse indicates whether the input voltage $U_{\mathrm{g}}$ is bigger than the pilot voltage $U_{\text {ref }}$ or not. This impulse operates the thyristors of the power module.

Fig. 8 shows the operation of the thyristor by the deviation of the voltage from the nominal one.

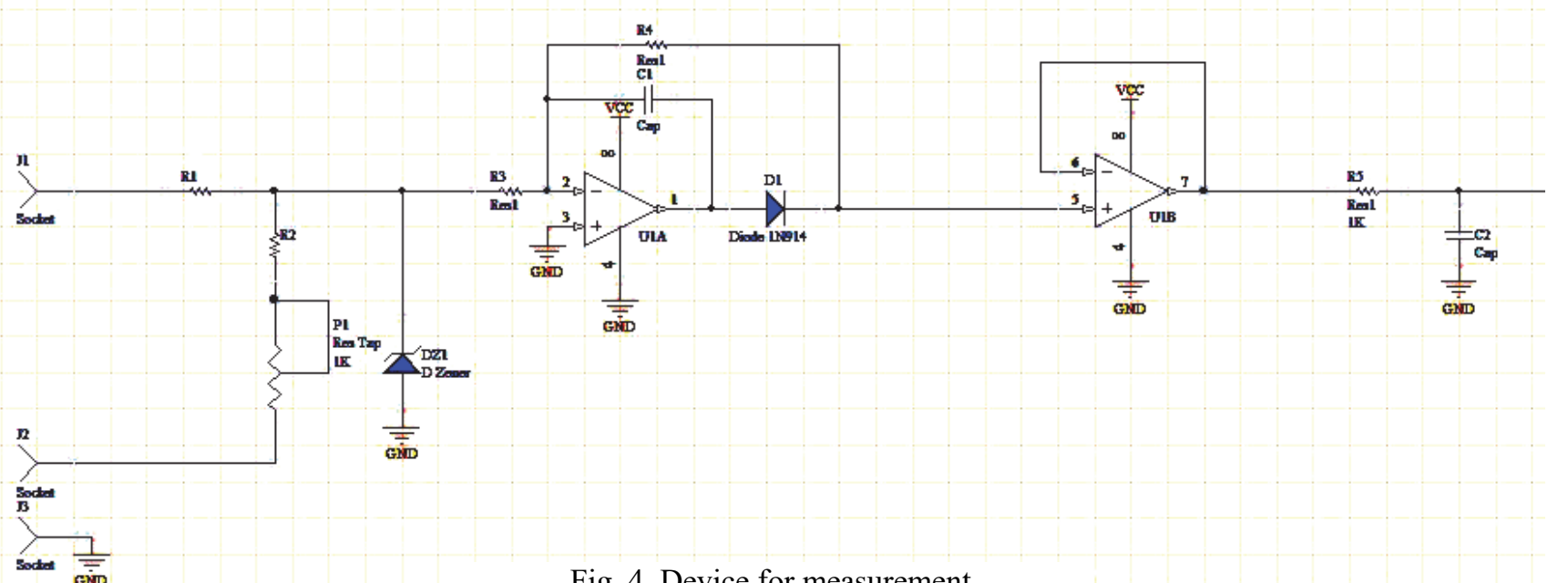

Fig. 4. Device for measurement and droop tune (DMDT).

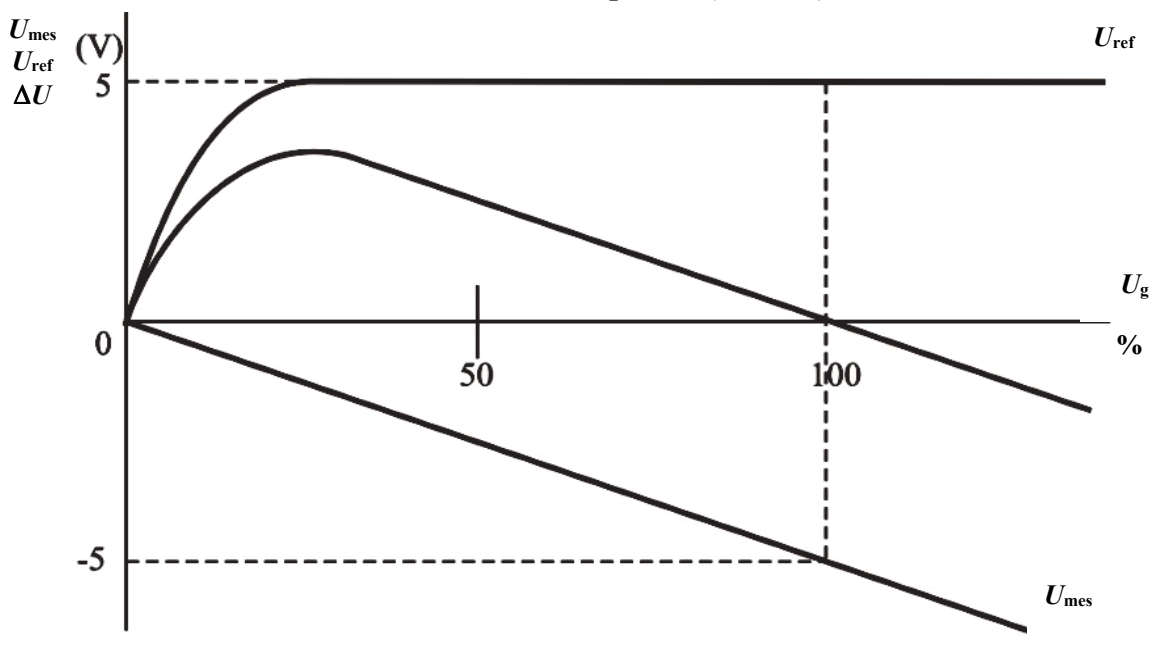

Fig. 5. Graph of the relations of the voltages.

Fig. 5 shows the dependence of the pilot voltage $U_{\text {ref }}$ on the change in the generator's voltage $U_{\mathrm{g}}$.

Fig. 6 presents the scheme of a power module and synchronization. The power module ensures the supply of all modules of the automatic voltage regulator. The three-phase voltage of the generator is transformed by a transformer and is stabilized.

Fig. 7 presents power module and synchronization scheme. The power module is operated by the comparator. It turns on for a certain period of time, which results in a bigger or smaller amount of supplying voltage of the excitation winding.
Fig. 9 presents the pulse-width modulation scheme and PID controller. This module forms the law of PID controlling according to which the voltage regulator functions and is presented by the formula:

$$
U=k_{p} \cdot U_{\mathrm{mes}}+\frac{1}{T_{i}} \int U_{\mathrm{mes}} d t+T_{d} \cdot \frac{d U_{\mathrm{mes}}}{d t} .
$$

The main part is the operation amplifier which ensures the work of the proportional-integral-differential (PID) controller. The deviation of the generator's voltage $\Delta U$ is amplified, and this amplified difference $\Delta U^{\prime}$ is proportional to the integral of the entry voltage and it enters the comparator. 


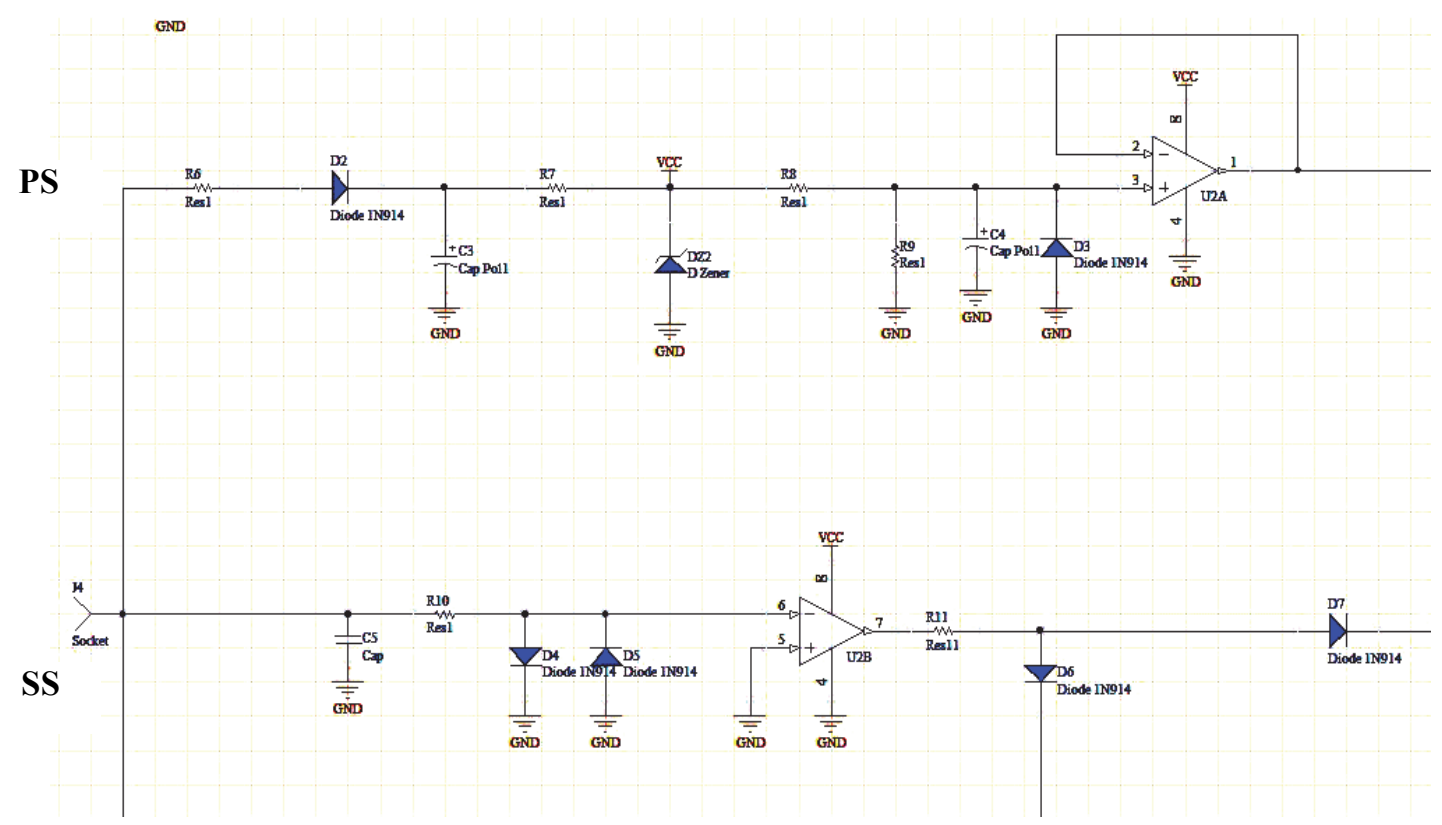

Fig. 6. Power supply and synchronization scheme.

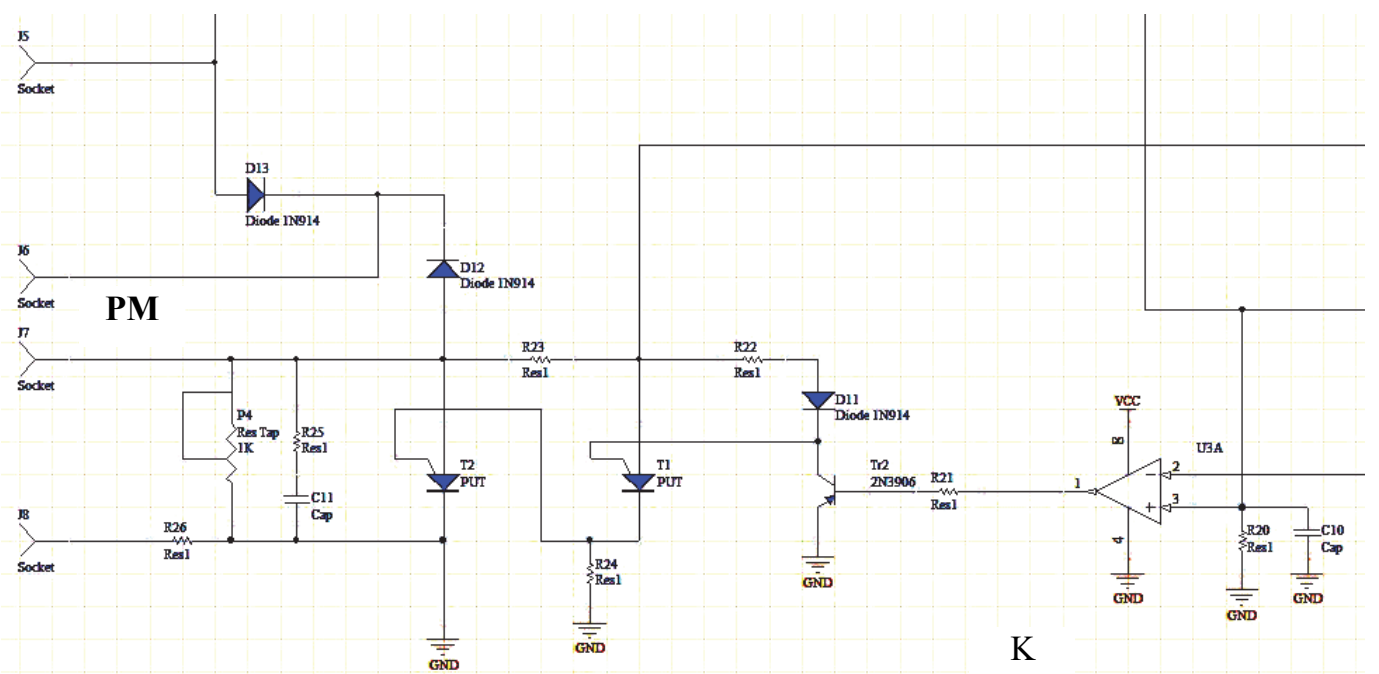

Fig. 7. Proportional-integral-differential controller and $U / f$ limiter.
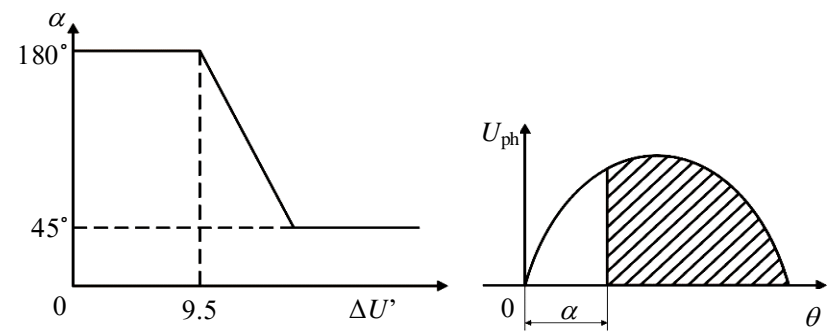

Fig. 8. Operation of the thyristor by the deviation of the voltage from the nominal one.

+Synchronization scheme (SS) is a functional generator which sends impulses by means of the comparator which operates the pulse-width modulation scheme.
The electrical protection module U/f transfers impulses which lock the power module at a lower frequency of rotation of the generator - up to $30 \mathrm{~Hz}$, which results in a lower voltage supply to the excitation winding. 


\section{INVESTIGATION OF THE WORK OF THE AUTOMATIC VOLTAGE REGULATOR}

The work of the developed automatic voltage regulator has been tested. For that purpose, different disturbances were simulated. On waveforms Figure 10 to Figure 19 demonstrate the results of the investigations: the waveforms achieved during the static and transitional regimes of the work of a synchronous generator, caused by direct starting of the induction motor (IM $0.93 \mathrm{~kW} ; 2850 \mathrm{rpm}$ ).

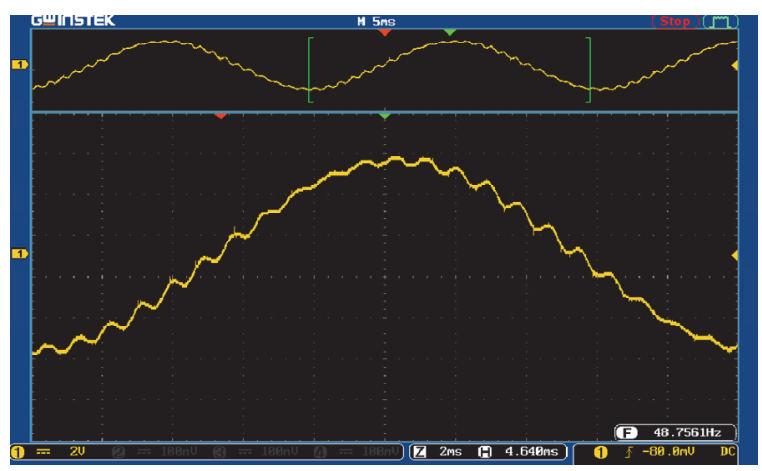

Fig. 10. Stator voltage of a synchronous generator with compound excitation without AVR.

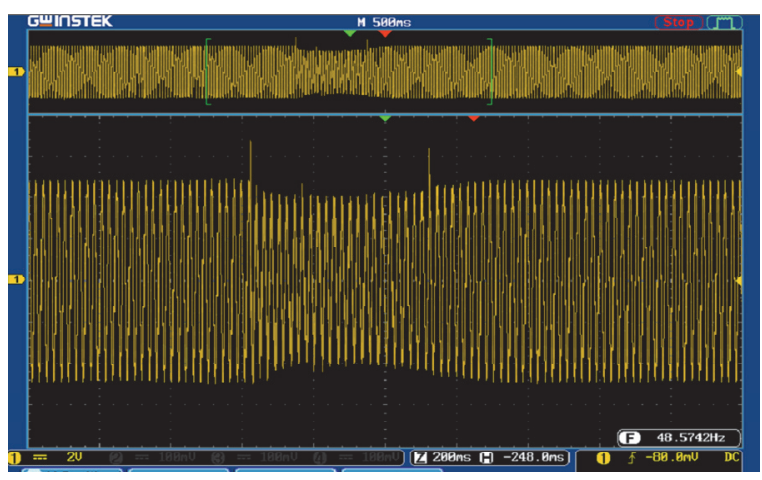

Fig. 11. Transient stator voltage of a synchronous generator at direct starting of the induction motor.

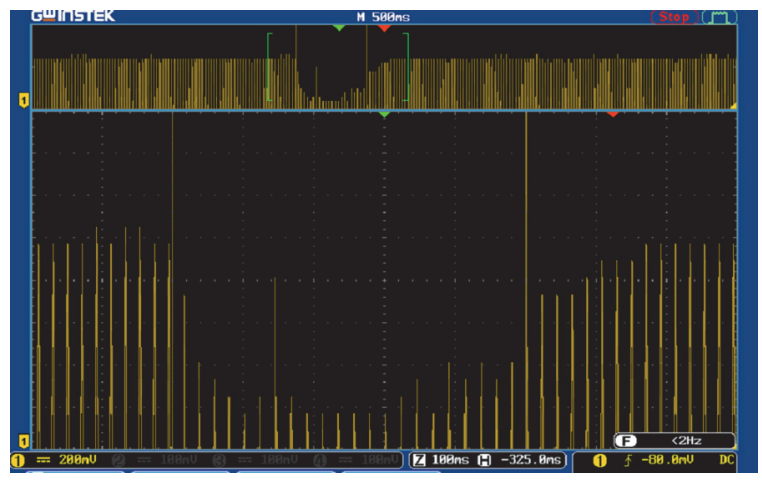

Fig. 12. Transient stator voltage of a synchronous generator at direct starting of the induction motor.

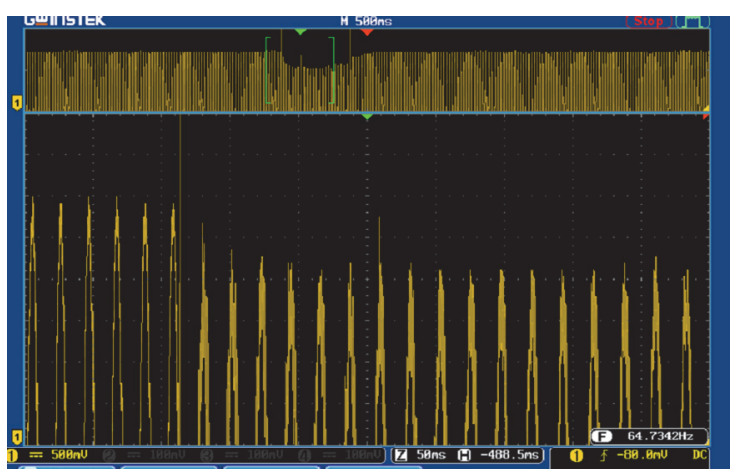

Fig. 13. Transient stator voltage of a synchronous generator on induction motor direct start without AVR

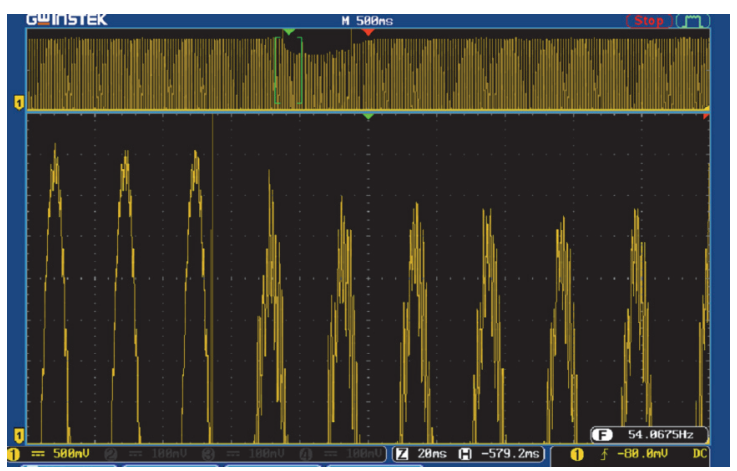

Fig. 14. Transient stator voltage of a synchronous generator on induction motor direct start without AVR.

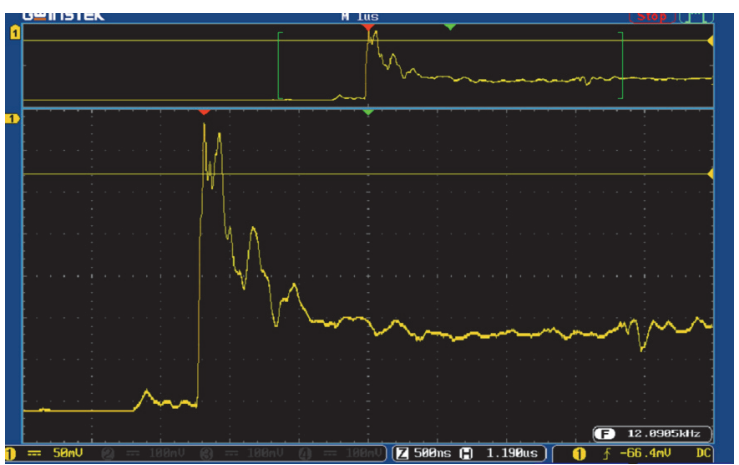

Fig. 15. Transient field excitation of a synchronous generator on induction motor direct start.

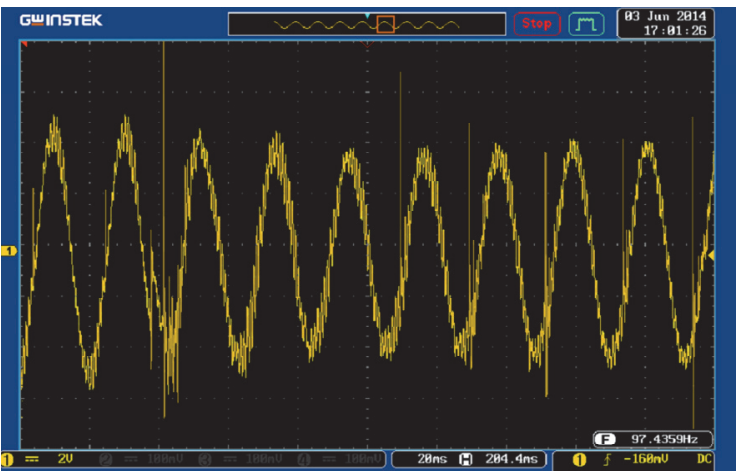

Fig. 16. Transient stator voltage of a synchronous generator on induction motor direct start without AVR. 


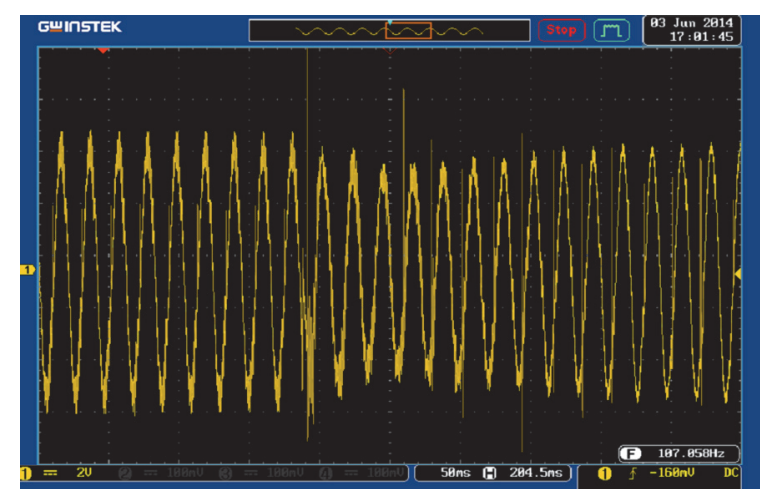

Fig. 17. Transient stator voltage of a synchronous generator on induction motor direct start with AVR.

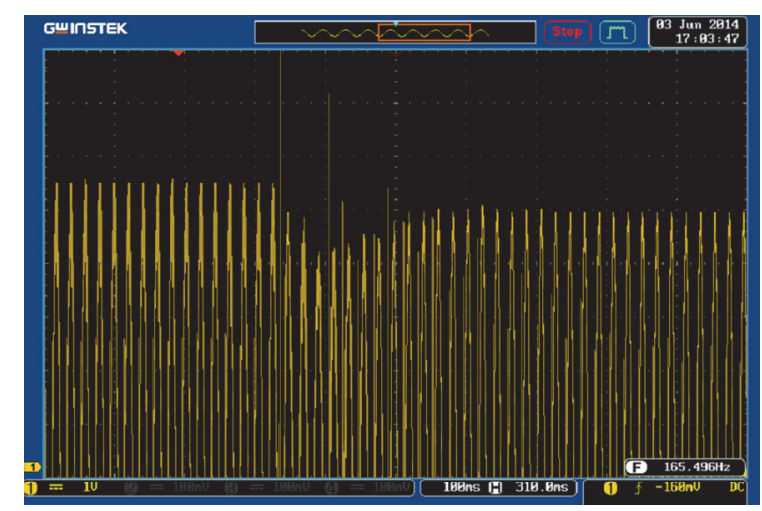

Fig. 18. Transient stator voltage of a synchronous generator on induction motor direct start with AVR.

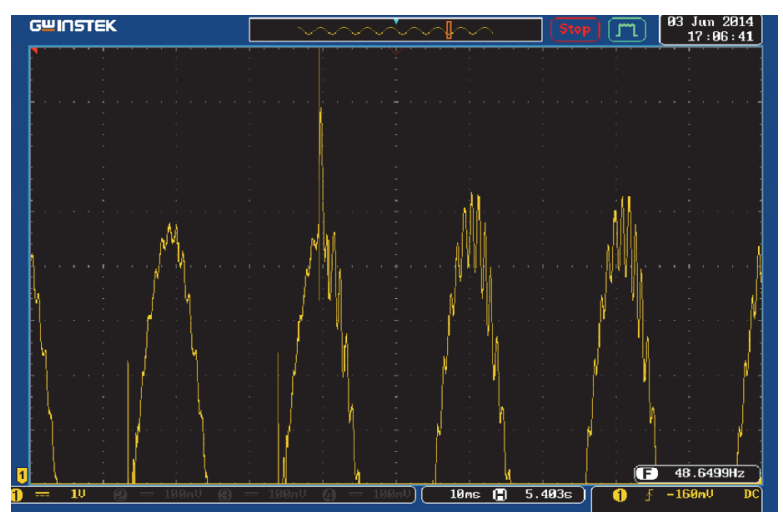

Fig. 19. Transient stator voltage of a synchronous generator on induction motor direct start with AVR.

\section{CONCLUSiON}

The compound type of the electronic automatic voltage regulator of ship's synchronous generators is used because of its high reliability and very good dynamic characteristics. The article describes the developed electronic automatic volt- age regulator. The proportional-integral-differential regulator, which was developed, improves the static and dynamic characteristics of the generator. Part of the test results of AVR is presented. They demonstrate the high accuracy of regulation of the voltage of the ship's synchronous generator and its very good dynamic characteristics at various problematic circumstances. The tests of the developed AVR have shown improvement of all parameters of the regulation of the voltage of the synchronous generator, which are given in the following table.

TABLE I

TESTS OF THE DEVELOPED AVR

\begin{tabular}{|l|c|c|}
\hline \multicolumn{1}{|c|}{$\begin{array}{c}\text { Requirements for classification } \\
\text { organization }\end{array}$} & $\begin{array}{c}\text { Compound system } \\
\text { excitation }\end{array}$ & $\begin{array}{c}\text { Compound } \\
\text { system excita- } \\
\text { tion \& AVR }\end{array}$ \\
\hline $\begin{array}{l}\text { Static stator voltage accuracy: } \\
\pm 2.5 \%\end{array}$ & $\pm 5 \%$ & $\pm 0.3 \%$ \\
\hline $\begin{array}{l}\text { Stator voltage droop (150\% load, } \\
\cos \varphi=0.8): \pm 10 \%\end{array}$ & $\pm 10 \%$ & $\pm 2.5 \%$ \\
\hline Sudden stator voltage sag: $\pm 20 \%$ & $\pm 10 \%$ & $\pm 2 \%$ \\
\hline Total harmonic distortion: $5 \%$ & $5 \%$ & $1 \%$ \\
\hline $\begin{array}{l}\text { Durable short-cut current } \\
\left(t_{\text {s.c. }}=2 \text { s): } 3 \text { p.u. }\right.\end{array}$ & 4 p.u. & 4 p.u. \\
\hline
\end{tabular}

\section{REFERENCES}

[1] S.-H. Park, S.-K. Lee, S.-W. Lee, J.-S. Yu, S.-S. Lee, C.-Y. Won, “Output Voltage Control of a Synchronous Generator for Ships Using Compound Type Digital AVR," in $31^{\text {st }}$ Int. Telecommunications Energy Conf., 2009, INTELEC 2009, Oct. 18-22, 2009, pp. 1-6.

[2] http://dx.doi.org/10.1109/intlec.2009.5352002

[3] C. S. Hoong and T. Taib, "Development of Automatic Voltage Regulator for Synchronous Generator," in Proc. of Power and Energy Conf. PEC 2004, Nov. 29-30, 2004, pp. 180-184. http://dx.doi.org/10.1109/pecon.2004.1461639

[4] W.-M. Lin and C.-L. Lee, "Discussion on Parameters Setting and Loss of Exciter Time Constant Compensation in Excitation System," in 2006 Int. Conf. on Power System Technology, POWERCON 2006, Chongqing, China Oct. 22-26, 2006, pp. 1-6. http://dx.doi.org/10.1109/icpst.2006.321674

[5] K. Zalewska, W. Rebizant and R. Kawecki, "Comparative Analysis of Different Types of Generator Voltage Controllers," in Proc. of the IEEE $44^{\text {th }}$ Int. Universities Power Eng. Conf., UPEC, Sept. 1-4, 2009, pp. 1-4.

[6] M. Htay, and K. S. Win, "Design and Construction of Automatic Voltage Regulator for Diesel Engine Type Stand-alone Synchronous Generator," in Proc. of World Academy of Science: Eng. and Technol., Aug. 2008, vol. 44, pp. 763-769.

[7] S. Caiqin, L. Chengqiu and S. Chengjun, "Simulation and Implementation of Marine Generator Excitation System with PSS," in Proc. of the 2009 IEEE Int. Conf. on Mechatronics and Automation, Aug. 9-12, 2009, Changchun, China, pp. 839-844. http://dx.doi.org/10.1109/icma.2009.5246266

[8] N. F. Djagarov and M. B. Bonev, "A Fast Adaptive Power System Stabilizer,” in IFAC Symp. on Power Plant \& Power Systems Control, 2003, Seoul, Korea, Pre-prints vol. III, pp. 1129-1134.

[9] N. F. Djagarov and T. Lazarov, "Automatic Voltage Regulator for a Ship's Synchronous Generator," in Proc. of 12th Int. Conf. on Marine Science and Technol., Sept. 25-27, 2014, Varna, Bulgaria, pp. 132-137.

[10] N. F. Djagarov, Ship's Electrical Power Systems, Technical University of Varna, 1997, p. 324. 